\title{
Study the Structure, Morphology and Vibration Modes for $\mathrm{K}_{2} \mathrm{CrO}_{4}$ and $\mathrm{K}_{2} \mathrm{Cr}_{2} \mathrm{O}_{7}$
}

\author{
Hasanain Saad Azeez and Mohammad R. Mohammad \\ Department of Applied Sciences, University of Technology, Baghdad-Iraq.
}

\begin{abstract} $\mathrm{K}_{2} \mathrm{CrO}_{4}$, and $\mathrm{K}_{2} \mathrm{Cr}_{2} \mathrm{O}_{7}$ powders. Microscopy (AFM) technique.

Keywords: structural, morphological, vibrational.

\section{Introduction}

\subsection{Potassium chromate $\mathrm{K}_{2} \mathrm{CrO}_{4}$ :}

It is an inorganic solid compound, which has a yellow color for the potassium salt of chromateanion. It is known as a laboratory chemical material, whereas sodium chromate is an important in industrial material [1][2].
\end{abstract}

In this work, the X-ray diffraction (XRD) measurement have been done to study the structure of

The morphology of $\mathrm{K}_{2} \mathrm{CrO}_{4}$, and $\mathrm{K}_{2} \mathrm{Cr}_{2} \mathrm{O}_{7}$ thin films has been studied by using Atomic Force

Modes of vibrations for both $\mathrm{K}_{2} \mathrm{CrO}_{4}$, and $\mathrm{K}_{2} \mathrm{Cr}_{2} \mathrm{O}_{7}$ compounds were measured and discussed using Fourier transform infrared spectroscopy (FTIR). [DOI: 10.22401/JNUS.20.2.09]

\subsection{Potassium dichromate K2Cr2O7:}

Potassium dichromate is one of the crystalline inorganic chemical reagent.
Hexavalent chromium compounds are harmful to health. $\mathrm{K}_{2} \mathrm{Cr}_{2} \mathrm{O}_{7}$ is widely used in laboratories and industry as an oxidizing agent because it is not deliquescent. Potassium dichromate looks very bright and red-orange color [3][4].

Table (1) shows the physical and chemical properties of both $\mathrm{K}_{2} \mathrm{CrO}_{4}$ and $\mathrm{K}_{2} \mathrm{Cr}_{2} \mathrm{O}_{7}$ compounds.

Table (1)

Shows physical and chemical properties for $\mathrm{K}_{2} \mathrm{CrO}_{4}, \mathrm{~K}_{2} \mathrm{Cr}_{2} \mathrm{O}_{7}$ [1-4].

\begin{tabular}{|l||c||c||}
\hline \hline physical and chemical properties & Potassium chromate & Potassium dichromate \\
\hline \hline Molecular Formula & $\mathrm{K}_{2} \mathrm{CrO}_{4}$ & $\mathrm{~K}_{2} \mathrm{Cr}_{2} \mathrm{O}_{7}$ \\
\hline \hline Molecular Weight & $194.19 \mathrm{~g} / \mathrm{mol}$ & $294.18 \mathrm{~g} / \mathrm{mol}$ \\
\hline \hline Physical State & Poly crystalline powder & Poly crystalline powder \\
\hline \hline Appearance & Yellow coloured powder & Orange coloured powder \\
\hline \hline PH $\left(5 \%, 20^{0} \mathrm{C}\right)$ & $8.6-9.8$ & $3.7-4$ \\
\hline \hline Density & $2.73 \mathrm{~g} / \mathrm{cm}^{3}$ & $2.676 \mathrm{~g} / \mathrm{cm}^{3}$ \\
\hline \hline Melting Point & $968^{0} \mathrm{C}$ & $398^{0} \mathrm{C}$ \\
\hline \hline Boiling Point & $1000{ }^{0} \mathrm{C}$ & $500{ }^{0} \mathrm{C}$ \\
\hline \hline Solubility in Water $\left(20^{0} \mathrm{C}\right)$ & $629 \mathrm{~g} / \mathrm{L}$ & $125 \mathrm{~g} / \mathrm{L}$ \\
\hline \hline Solubility in Alcohol & Insoluble & Insoluble \\
\hline \hline Refractive Index $\left(\mathrm{n}_{\mathrm{D}}\right)$ & 1.74 & 1.738 \\
\hline \hline
\end{tabular}

\section{Expermantal procedure}

\subsection{Prepartion of $\mathrm{K}_{2} \mathrm{CrO}_{4}, \mathrm{~K}_{2} \mathrm{Cr}_{2} \mathrm{O}_{7}$ thin films:}

\subsubsection{Substrate preparation:}

For spin coating $\left(\mathrm{K}_{2} \mathrm{CrO}_{4}\right)$ or $\left(\mathrm{K}_{2} \mathrm{Cr}_{2} \mathrm{O}_{7}\right)$, thin films have used glass substrates. At the beginning, the substrates have been cleaned by diluted hydrochloric acid $(\mathrm{HCl})$, ethanol and distilled water, then using electrical oven supplied by (Jard) at temperature $\left(80 \mathrm{C}^{0}\right)$ to dry the substrate.

\subsubsection{Film spin coating:}

Potassium chromate powder or potassium dichromate powder is grinded with grinder to get fine powder then the ethanol is add to fin 
powder and enter the precipitate solution into the ultrasonic vibration for (15) minutes to become homogeneous solution. Spin coating is applied by adding a drops of homogeneous solution by Pipette to glass slide to get thin film.

The summary of spin coating conditions is showed in Table (2).

Table (2)

Summary of spin coating conditions.

\begin{tabular}{|c||c||}
\hline parameters & values \\
\hline \hline Speed & $3000(\mathrm{rpm})$ \\
\hline \hline Time & $15 \mathrm{sec}$ \\
\hline \hline acclr & $5 \mathrm{sec}$ \\
\hline Temperature & $25^{\circ} \mathrm{C}$ \\
\hline
\end{tabular}

\section{Results and discussions}

\subsection{X- ray diffraction (XRD):}

$\mathrm{K}_{2} \mathrm{CrO}_{4}$ powder is grinded with grinder to get fine powder in order to get perfect crystallinity of material as clarified in Fig.(1A). The characteristics peaks of X-ray diffraction pattern for $\mathrm{K}_{2} \mathrm{CrO}_{4}$ come at $2 \theta=29.0750^{\circ}, \quad 29.9389^{\circ}, \quad 20.8283^{\circ}$ which correspond to miller indices (211),( 031),(111) respectively; according to the JCPDS no.15-365 data. And all the hexagonal phase (Orthorhombic structure) of $\mathrm{K}_{2} \mathrm{CrO}_{4}$ is appeared in all diffraction peaks. The high purity of $\mathrm{K}_{2} \mathrm{CrO}_{4}$ compound indicated disappearance peak of impurity.

The lattice spacing (d) could be calculated by using Bragg's law; to calculate (d) lattice spacing where $n_{i}=1$.

$2 \mathrm{~d} \sin \theta=\mathrm{n}_{\mathrm{i}} \lambda$

where $\lambda$ of the $\mathrm{X}$-Ray wavelength is $\left(1.54 \mathrm{~A}^{0}\right), \theta$ is the diffraction angle in degree and $\mathrm{n}_{\mathrm{i}}=1$.

Also the grain size (D) can be calculated by using Scherrer equation:

$\mathrm{D}=\frac{\mathrm{k} \lambda}{\beta \cos \theta}$

where $\mathrm{k}=$ is a constant $(0.89<\mathrm{k}<1)$, $\beta=$ FWHM. (full width at half maximum) of the diffraction peak.

The particle size (D) is calculated using equation (2).The average crystallite size D has been calculated from equation (2) to be $12.95 \mathrm{~nm}$.

$\mathrm{K}_{2} \mathrm{Cr}_{2} \mathrm{O}_{7}$ powder is grinded with grinder to get fine powder in order to get good crystallinity of material as shown in Fig. (1B). The X-ray diffraction pattern shows characteristic peaks of $\mathrm{K}_{2} \mathrm{Cr}_{2} \mathrm{O}_{7}$ at $2 \theta=27.1046^{\circ}, \quad 25.7088^{\circ}, \quad 24.4468^{\circ}$ which correspond to miller indices $(2 \overline{1} 1),(210),(0 \overline{1} 2)$ respectively according to the JCPDS no.0.270380 data. All the diffraction peaks refer to hexagonal phase (Anorthic Triclinic structure) of $\mathrm{K}_{2} \mathrm{Cr}_{2} \mathrm{O}_{7}$ peaks of impurity which do not be observed, that refers to the high purity of $\mathrm{K}_{2} \mathrm{Cr}_{2} \mathrm{O}_{7}$ compound.

The particle size calculated using equation (2) shows an average crystallite size D of $19.91 \mathrm{~nm}$.

Table (3) shows XRD details for $\mathrm{K}_{2} \mathrm{CrO}_{4}$, $\mathrm{K}_{2} \mathrm{Cr}_{2} \mathrm{O}_{7}$ powders. 
Table (3)

$\mathrm{XRD}$ for $\mathrm{K}_{2} \mathrm{CrO}_{4}$ and $\mathrm{K}_{2} \mathrm{Cr}_{2} \mathrm{O}_{7}$ powder.

\begin{tabular}{|c||c|c||c||c||c||}
\hline Material & $\begin{array}{c}\mathbf{2 \theta} \\
(\mathbf{d e g} .)\end{array}$ & $\begin{array}{c}\text { Plane } \\
\text { (hkl) }\end{array}$ & $\begin{array}{c}\text { FWHM } \\
\text { (deg.) }\end{array}$ & $\begin{array}{c}\text { Grain size } \\
\text { (nm) }\end{array}$ & $\begin{array}{c}\text { d } \\
\left(\mathbf{A}^{\mathbf{0}}\right)\end{array}$ \\
\hline \hline $\mathrm{K}_{2} \mathrm{CrO}_{4}$ & $29.0750^{\circ}$ & 211 & 0.26980 & 15.21 & 3.06876 \\
& $29.9389^{\circ}$ & 031 & 0.36830 & 11.168 & 2.98215 \\
& $20.8283^{\circ}$ & 111 & 0.32350 & 12.489 & 4.26140 \\
$\mathrm{~K}_{2} \mathrm{Cr}_{2} \mathrm{O}_{7}$ & $27.1046^{\circ}$ & $2 \overline{1} 1$ & 0.24850 & 16.448 & 3.28720 \\
& $25.7088^{\circ}$ & 210 & 0.25470 & 16.002 & 3.46242 \\
& $24.4468^{\circ}$ & $0 \overline{1} 2$ & 0.14900 & 27.287 & 3.63823 \\
\hline
\end{tabular}
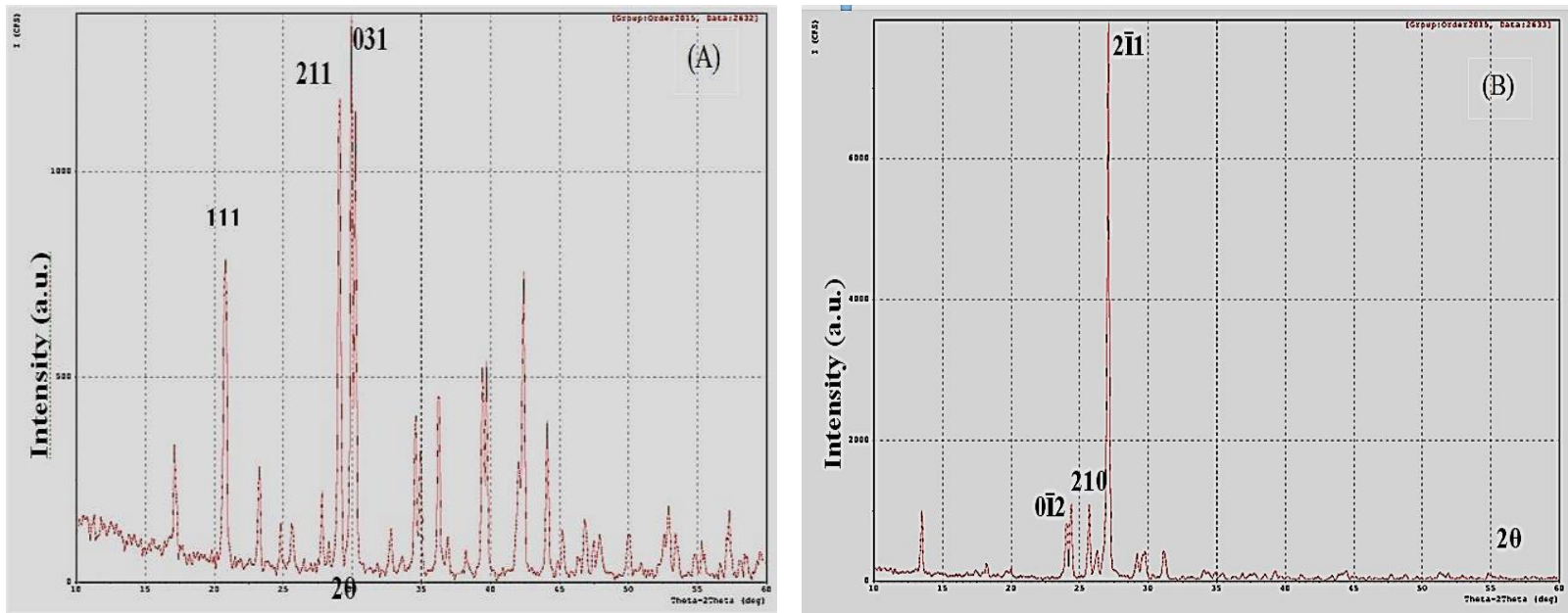

Fig.(1): The XRD spectra of the (A) $\mathrm{K}_{2} \mathrm{CrO}_{4}$ (B) $\mathrm{K}_{2} \mathrm{Cr}_{2} \mathrm{O}_{7}$ powders.

\subsection{Atomic Force Microscopy (AFM):}

In sensing devices application the morphology plays an important role to the physical and optical properties. Fig. $(2$ A) refers to the 3D, 2D AFM images of the $\mathrm{K}_{2} \mathrm{CrO}_{4}$ thin film, while Fig. (2 B) refers to the $3 \mathrm{D}, 2 \mathrm{D}$ AFM images of the $\mathrm{K}_{2} \mathrm{Cr}_{2} \mathrm{O}_{7}$ thin film.

(A)

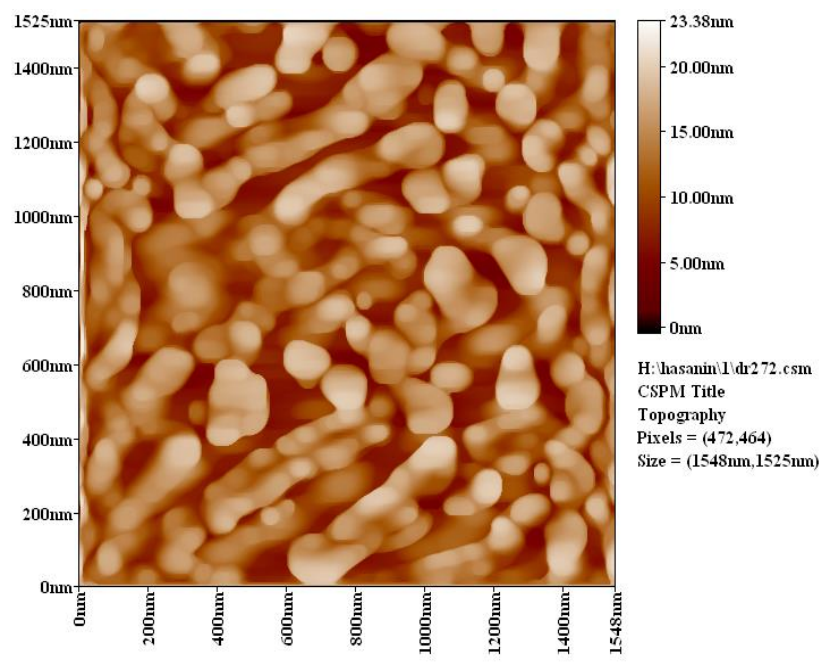


(B)
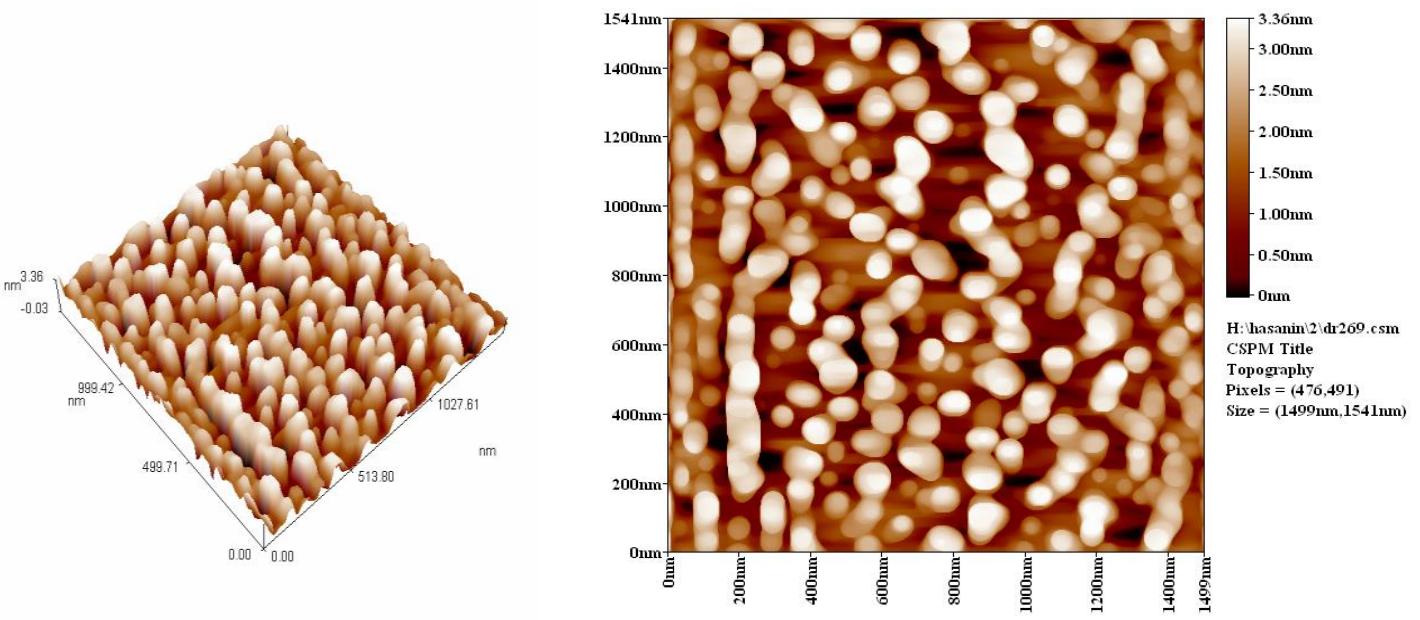

Fig.(2): Atomic force microscopy images at $3 \mathrm{D}$ and $2 \mathrm{D}$ of the (A) $\mathrm{K}_{2} \mathrm{CrO}_{4}$ thin film, (B) $\mathrm{K}_{2} \mathrm{Cr}_{2} \mathrm{O}_{7}$ thin film.

Fig.(3) refers to the granularity cumulation distribution chart of the $\mathrm{K}_{2} \mathrm{CrO}_{4}, \mathrm{~K}_{2} \mathrm{Cr}_{2} \mathrm{O}_{7}$ thin films.

The calculated values of average grain size and roughness are shown in Table (4).

(A)

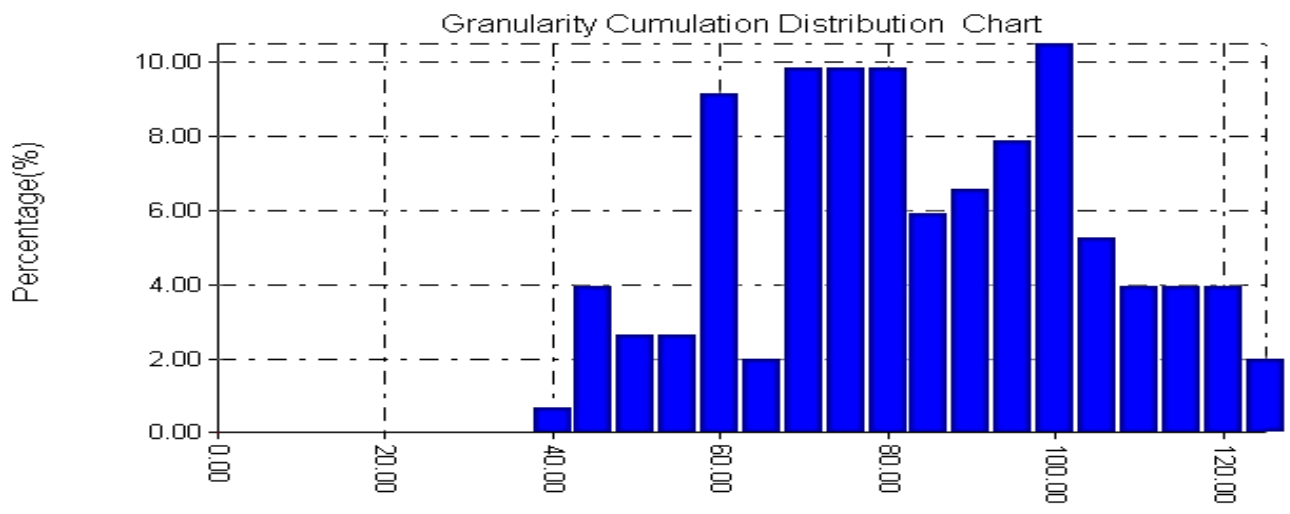

Diameter( $(\mathrm{nm})$

(B)

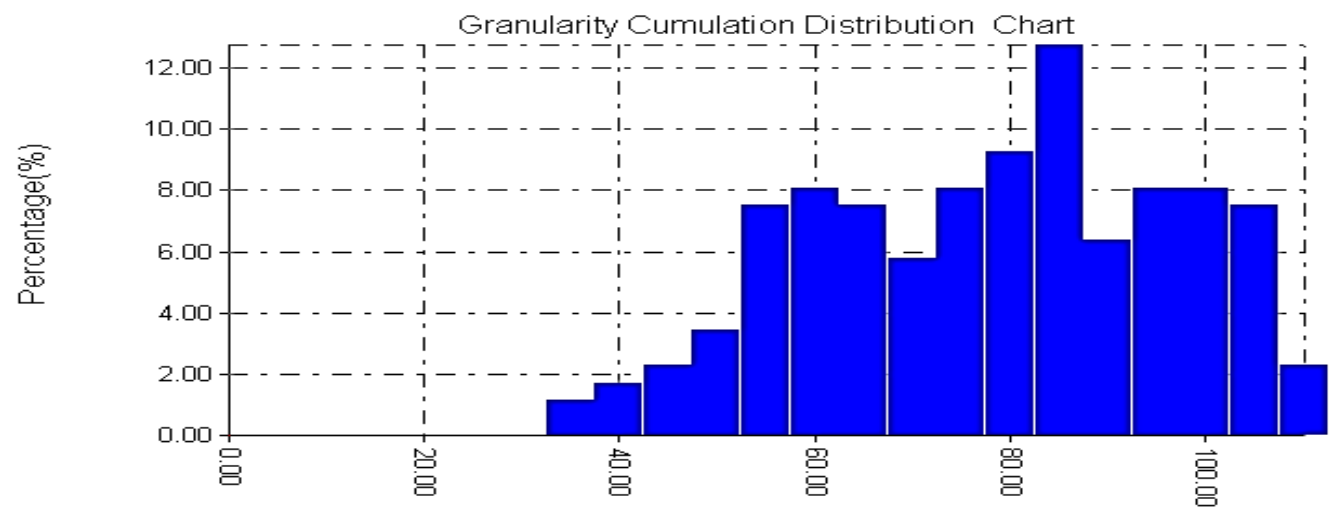

Diameter(nm)

Fig.(3): Granularity cumulation. distribution chart of the (A) $\mathrm{K}_{2} \mathrm{CrO}_{4}$ and $\left(\mathrm{B}^{\mathrm{K}} \mathrm{K}_{2} \mathrm{Cr}_{2} \mathrm{O}_{7}\right.$ thin films. 
Table (4)

The value of average grain size and roughness.

\begin{tabular}{|c|c|c|c|}
\hline Material & Average. grain size (nm) & Roughness(nm) & Root,, Mean Square (nm) \\
\hline \hline $\mathrm{K}_{2} \mathrm{CrO}_{4}$ & 81.23 & 3.34 & 3.96 \\
\hline $\mathrm{K}_{2} \mathrm{Cr}_{2} \mathrm{O}_{7}$ & 75.53 & 0.815 & 0.974 \\
\hline \hline
\end{tabular}

\subsection{Fourier Transform Infrared} Spectroscopy (FTIR):

Fig.(4A) shows the FTIR spectrum of $\mathrm{K}_{2} \mathrm{CrO}_{4}$ powder. The $\mathrm{CrO}_{4}{ }^{-2}$ ion has tetrahedral structure belonging to $\mathrm{T}_{\mathrm{d}}$ point group. This ion has four fundamental bands; $v_{1}$ (symmetric stretching band), $v_{2}$ (anti- symmetric stretching band), $v_{3}$ (symmetric bending band), $v_{4}$ (antisymmetric bending band). The $v_{1}$ and $v_{2}$ vibrations are Raman active only (this is because there are only changes in magnitude or direction of polariziblity), while $v_{3}$ and $v_{4}$ vibrations are infrared active only (this is because there are changes in magnitude of dipole moment).

From the previous studies that a free chromate ion as a result of its $\mathrm{T}_{\mathrm{d}}$ symmetry has four normal modes of vibration represented by $\mathrm{A}_{1}, \mathrm{E}_{1}, \mathrm{~T}_{1}$ and $\mathrm{T}_{2}$ with frequencies $v_{1}\left(847 \mathrm{~cm}^{-1}\right)$, $v_{2}\left(348 \mathrm{~cm}^{-1}\right), v_{3}\left(884 \mathrm{~cm}^{-1}\right)$, and $v_{4}\left(368 \mathrm{~cm}^{-1}\right)$ respectively [5][6].

Fig.(4B) shows the FTIR spectrum of $\mathrm{K}_{2} \mathrm{Cr}_{2} \mathrm{O}_{7}$ powder. The weak peak of $\mathrm{K}_{2} \mathrm{Cr}_{2} \mathrm{O}_{7}$ at $555.52 \mathrm{~cm}^{-1}$ is due to $\mathrm{Cr}-\mathrm{O}-\mathrm{Cr}$ symmetric stretching vibration, while the very strong peak at $754.19 \mathrm{~cm}^{-1}$ is due to $\mathrm{Cr}-\mathrm{O}-\mathrm{Cr}$ anti symmetric stretching vibration, the medium strong peak at $891.14 \mathrm{~cm}^{-1}$ is due to $\mathrm{Cr}-\mathrm{O}_{3}$ symmetric stretching vibration (ms) and the very strong peak at $935.51 \mathrm{~cm}^{-1}$ is due to $\mathrm{Cr}-\mathrm{O}_{3}$ anti symmetric stretching vibration (vs) [7] [8].

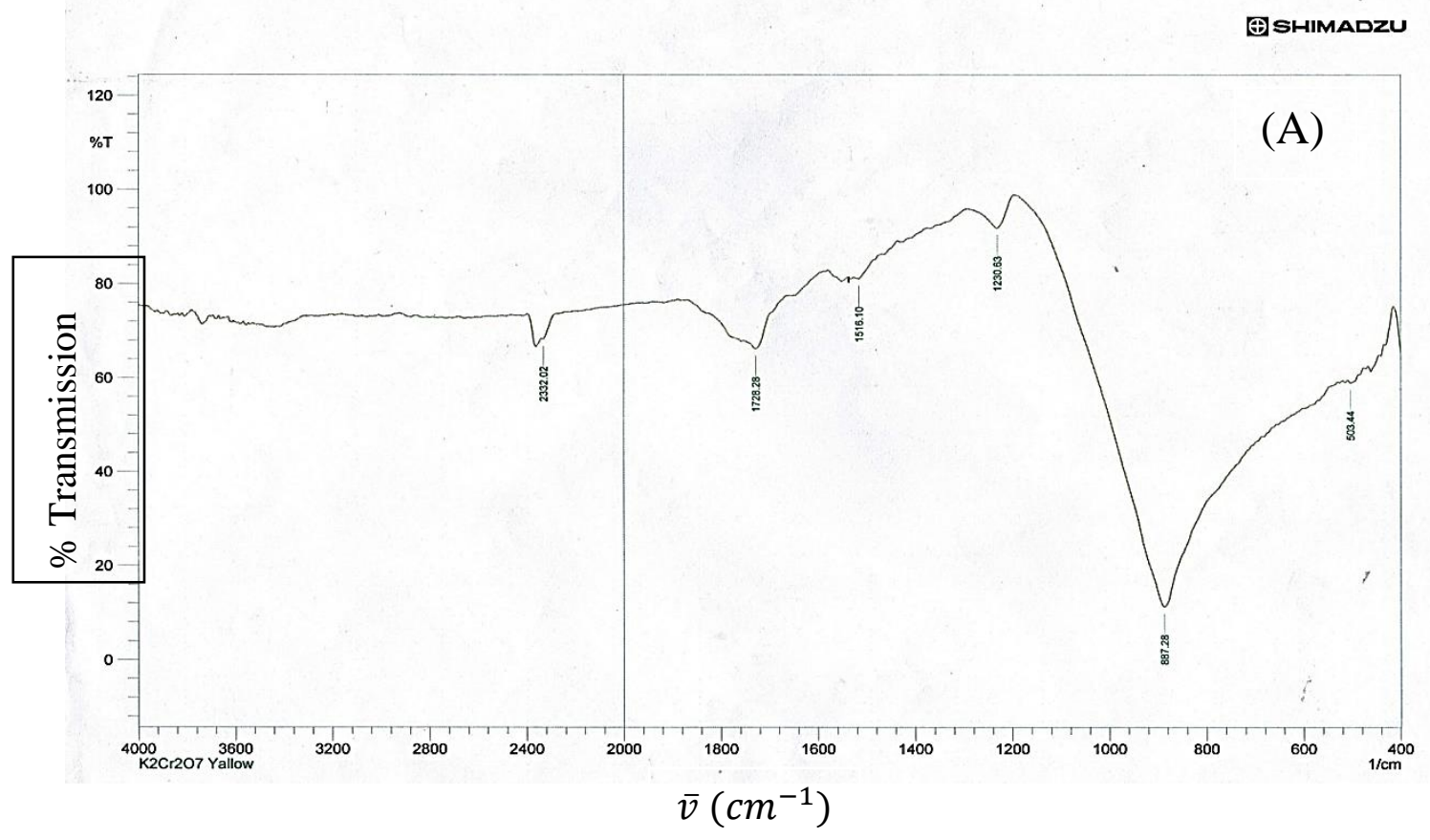




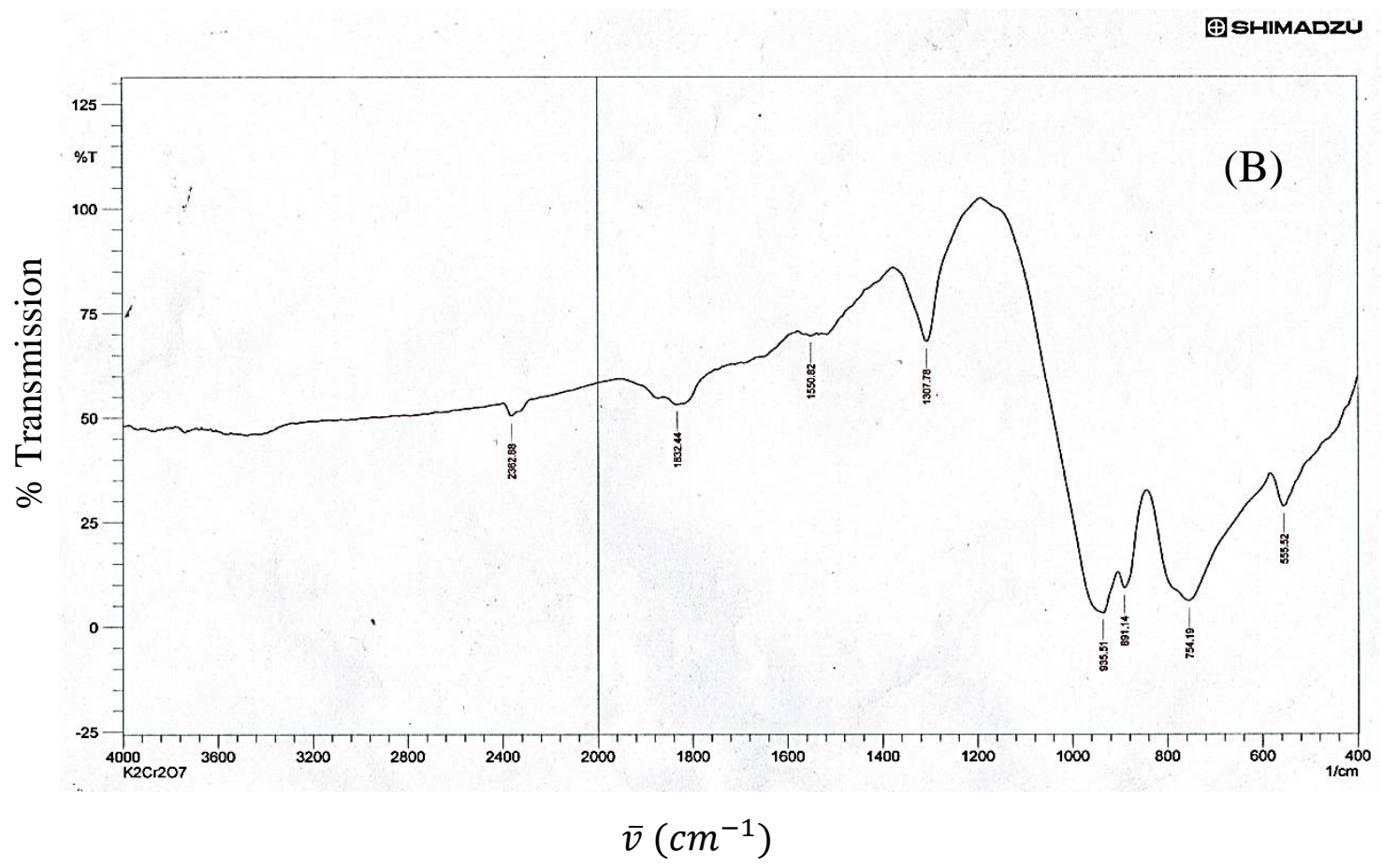

Fig.(4): Shows FTIR spectra for (A) $\mathrm{K}_{2} \mathrm{CrO}_{4}$ powder (B) $\mathrm{K}_{2} \mathrm{Cr}_{2} \mathrm{O}_{7}$ powder.

\section{Conclusions}

1. The X-ray diffraction (XRD) results showed that $\mathrm{K}_{2} \mathrm{CrO}_{4}$ and $\mathrm{K}_{2} \mathrm{Cr}_{2} \mathrm{O}_{7}$ nanoparticles powder have good crystallinity and in general the grain size of $\mathrm{K}_{2} \mathrm{CrO}_{4}$ compound was smaller than that of $\mathrm{K}_{2} \mathrm{Cr}_{2} \mathrm{O}_{7}$ compound.

2.The Atomic force microscopy (AFM) results showed that $\mathrm{K}_{2} \mathrm{CrO}_{4}$ compound was more average grain size and roughness than that for $\mathrm{K}_{2} \mathrm{Cr}_{2} \mathrm{O}_{7}$ compound.

3.FTIR spectra show absorption bands assigned both stretching and bending vibrations related to the two compound $\mathrm{K}_{2} \mathrm{CrO}_{4}$ and $\mathrm{K}_{2} \mathrm{Cr}_{2} \mathrm{O}_{7}$.

\section{References}

[1] Anger G., Halstenberg J., Hochgeschwender K., Scherhag Ch., Korallus U., Knopf H., Schmidt P., Ohlinger M., "Chromium Compounds", in Ullmann's Encyclopedia of Industrial Chemistry, Wiley - VCH, Weinheim, 2005.

[2] Lewis R.J., "Hazardous Chemicals Desk Reference", Wiley-Interscience, 6th Edition, 2008.

[3] Saha M., Srinivas C.R., Shenoy S.D., Balachandran C., Acharya S., "Footwear dermatitis", Contact Dermatitis, 28(5), 260264, 1993.
[4] Roto P., Sainio H., Reunala T., Laippala P., "Addition of ferrous sulfate to cement and risk of chromium dermatitis among construction workers", Contact Dermatitis, 34(1),43-50, 1996.

[5] Herzberg G., "Infrared and Raman Spectra of polyatomic molecules", D. Vanhastrand Co. Inc., New Yourk 1945.

[6] Chowdari B.V.R., Ravisekhar Y., "optical properties of dichromate centers in some lattices", chemical physics letters, 59(2), 311-315, 1978.

[7] Stammreich H., Bassi D., Sala O., Siebert H., "The vibrational spectrum of the dichromate ion" 13, 192-198, 1958.

[8] Carter R. L., Bricker C. E., "vibrational spectrum of Triclinic potassium dichromate", Spectroscopy letters, 2(8), 247-253, 1969. 